\title{
Límites de la libertad de expresión en el respeto a la intimidad: estudios de caso en el tratamiento de imágenes
}

\author{
Esperanza POUso TORRES \\ Universidade de Vigo \\ esperanzapousotorres@gmail.com
}

Recibido: 09/07/2012

Aceptado: 08/10/2012

\begin{abstract}
Resumen
En este artículo pretendemos realizar un análisis del tratamiento que los diarios españoles, $A B C, E l$ País y El Mundo, le dieron a las imágenes de los asesinatos de Sadam Husein, Osama Bin Laden y Muamar Gadafi. De este modo trataremos de aportar conclusiones sobre cuáles son los límites de la libertad de expresión desde el punto de vista del respeto a la intimidad, al honor y a la propia imagen, y en este caso el respeto al dolor. Veremos cómo la frontera entre lo público y lo privado se desdibuja y la línea entre lo privado y lo íntimo sufre el mismo proceso. Trataremos de buscar un punto de equilibrio entre el derecho que los ciudadanos tienen a ser informados y el derecho a la intimidad que tienen las víctimas.
\end{abstract}

Palabras clave: Intimidad, dolor, imagen, periodismo y derecho.

\section{Limits of the freedom of expression in the respect to the intimacy: case studies in the images treatment}

\begin{abstract}
In this article we have tried to analyse the treatment that the murders of Sadam Husein, Osama Bin Landen and Muamar Gadafi received in the Spanish papers (ABC, El País and El Mundo). We will try to reach a conclusion about the freedom of speech limits from a respect point of view to privacy, to honour and to one's own image and in this particular case the respect to grief. We will see how the limit between public and private blurs and how the same happens to the line between private and privacy. We will try to find a balance between the population's right to be informed and the victims' privacy rights.
\end{abstract}

Keywords: Privacy, pain, image, journalism and right.

\section{Referencia normalizada}

POUSO TORRES, Esperanza (2012): "Límites de la libertad de expresión en el respeto a la intimidad: estudios de caso en el tratamiento de imágenes". Estudios sobre el mensaje periodístico. Vol. 18, núm. especial noviembre, págs.: 721-728. Madrid, Servicio de Publicaciones de la Universidad Complutense.

Sumario: 1. Introducción. 2. Metodología y objeto de estudio. 3. Hipótesis planteadas. 4. Análisis fotográfico. 5. Conclusiones. 6. Referencias bibliográficas.

\section{Introducción}

El fundador de la red terrorista Al Qaeda y los dirigentes de dos países árabes han muerto de forma violenta a manos de países enemigos. Sadam Husein, el dictador implacable que gobernó Irak durante más de 20 años, murió en la horca en el 2006 a los 69 años de edad por los crímenes realizados contra la humanidad. Una operación de las fuerzas especiales de élite estadounidenses ponía fin, el 2 de mayo de 2011, a la vida de Osama Bin Laden tras realizar varios disparos en el asalto del comando a una mansión en la que se encontraba el líder árabe. En 2011, ocho meses de revolución y guerra contra el régimen dictatorial de Muamar Gadafi fueron suficientes para derrocar al que fuera dirigente de Libia durante más de 40 años. 
Atentados, guerras y revueltas envolvieron sus fallecimientos. Sin embargo, muchos intereses y revanchas fueron las que marcaron el camino de Husein, Bin Laden y Gadafi. En estas muertes, ¿se respetaron los Derechos Humanos?

Los espectadores tuvieron ocasión de presenciar desde todos los rincones del mundo estas caídas, vivirlas de cerca, seguirlas minuto a minuto y, quizás, ser partícipes de las mismas al alegrarse y celebrar sus fallecimientos. Cuando han pasado años desde lo sucedido, sigue viva la percepción de que tanto los medios de comunicación como los profesionales de la información pudieron desempeñar su labor con mayor rigor y profesionalidad. Todavía perdura en el tiempo, ya que podemos leer y observar las noticias que por aquel entonces publicaban los periódicos nacionales e internacionales.

Sin tener en cuenta lo que se narraba en las informaciones, y centrándonos estrictamente en las imágenes que se exhibieron de las muertes de los líderes, podemos percibir la falta de ética que aplicaron algunos profesionales de la información. La ejecución del ex dirigente de Irak, el asesinato del fundador de Al Qaeda y el linchamiento popular que sufrió Gadafi fueron emitidos mediante imágenes a través de la prensa y la televisión.

Por contextualizar y ponernos en situación, el caso más reciente, el linchamiento que sufrió Gadafi el pasado año por parte de los rebeldes. El asesinato del ex dirigente libio fue filmado y televisado, emitiendo al mundo la muerte de una persona detenida, quebrantando así las leyes de guerra, o lo que es lo mismo, la comisión de un delito. En las imágenes que ofrecieron los medios de comunicación, a nivel mundial, se puede ver una persona que pide clemencia mientras sus captores le golpean. Numerosos vídeos grabados por los propios rebeldes demuestran que el dictador fue golpeado, insultado, sufrió empujones y le apuntaron con una pistola la sien. Así, estas imágenes publicadas por los diarios nacionales e internacionales han dejado patentes las humillaciones a las que fue sometido Muamar Gadafi antes de su muerte.

En este contexto, con este trabajo queremos comprobar si los periódicos españoles, El Mundo, El País y $A B C$, difundieron imágenes de las víctimas, Sadam Husein, Osama Bin Laden y Muamar Gadafi, sin tener en cuenta los derechos a la propia imagen, a la intimidad y al honor, y violando, al mismo tiempo, los límites de la dignidad y la sensibilidad humana, llegando a alcanzar la morbosidad. Pretendemos llevar a cabo un análisis de las fotografías de prensa que difundieron los medios de comunicación en la cobertura de las muertes de los líderes. Tres noticias sucedidas en distintos lugares y en diferentes fechas, pero que tuvieron un alcance internacional debido a su gravedad e importancia y que guardan una estrecha relación en el tratamiento mediático que recibieron. Nos centraremos en el análisis de las fotografías que fueron exhibidas en los diarios la semana posterior a las muertes e intentaremos delimitar donde se encuentra el límite ético en el ámbito periodístico.

Tratamos de realizar, mediante las imágenes divulgadas por los medios de comunicación, un artículo que refleje uno de los malos hábitos de la prensa más usuales, sirviendo este estudio de reflexión para disminuir la tendencia a dar "malas noticias", y reforzar la línea que ofrezca una información exhaustiva y contrastada y afrontar uno de los retos de futuro del periodismo, el compromiso ético y solidario. 


\section{Metodología y objeto de estudio}

Para la realización del trabajo planteado se va a emplear una metodología de las disciplinas sociales, el análisis de contenido, en este caso fotográfico. En el mismo tomaremos como referencia cinco parámetros básicos: tres de contenido y dos de forma. En cuanto al análisis de contenido, tenemos en cuenta al sujeto que protagoniza la instantánea, dónde está ubicada la misma y, finalmente, describimos lo que observamos, la esencia de la imagen. Tratamos de obtener un análisis pormenorizado de la fotografía, consiguiendo así, de una forma clara, sencilla y concisa, introducirnos en el contexto en el que fue retratada. En cuanto al análisis de forma, nos referimos al tamaño de la instantánea y a su ubicación en el periódico, teniendo en cuenta la sección, la página y su ubicación. A través de esta observación sabemos qué importancia se le otorga a la imagen en la publicación.

Este modelo de análisis surge de la recopilación de los planteamientos metodológicos de Manuel Alonso y Luis Matilla (1990) y de Terry Barret (1990). Con el fin de ubicar el mensaje fotográfico dentro de la corriente informativa o de opinión y para realizar el análisis de la fotografía y su entorno, Carlos Abreu (2004) menciona los planteamientos de estos autores en un artículo sobre el análisis cualitativo de la fotografía de prensa.

Para concretar la metodología de nuestro trabajo nos hemos basado, grosso modo, en las ideas de Terry Barret sobre la crítica de fotografías. Su método desglosa la fotografía en varios niveles que van desde el descriptivo hasta el interpretativo pasando por lo explicativo y conceptualización teórica acerca de las fotos. Igualmente, considera el contexto que la rodea. Barret menciona a Ronald Barthes como ejemplo de cómo se puede analizar el significado de una fotografía a partir de los niveles denotativo -lo que se muestra- y connotativo -lo que se sugiere-

Partiendo de estas ideas hemos considerado que nuestro modelo debe asentarse en un doble análisis: por un lado analizaremos el contexto interno, lo que es evidente en la foto, y por otro el contexto externo, situación en la cual una fotografía es exhibida.

En cuanto al objeto de estudio, tenemos en cuenta la importancia mundial que tuvieron los sucesos que estudiamos, ya que las nuevas tecnologías de la comunicación convirtieron los fallecimientos de Sadam Husein, Osama Bin Laden y Muamar Gadafi en unos acontecimientos globales, pues ni el tiempo ni el espacio importaban, era posible seguir las muertes de los líderes desde cualquier punto del planeta.

Debido a la necesidad de acotar el campo de trabajo, nos centraremos en la prensa nacional. Concretamente en tres cabeceras fundamentales: El Mundo, El País y ABC. Tomaremos como referencia los 7 ejemplares de cada periódico posteriores a las muertes de los líderes. Específicamente, y siguiendo la cronología del tiempo, nos centraremos en las ediciones impresas de los periódicos emitidos en las siguientes fechas: del 30 de Diciembre de 2006 al 6 de Enero de 2007, del 1 de Mayo de 2011 al 8 de Mayo de 2011 y del 20 de Octubre de 2011 al 27 de Octubre de 2011. Por lo tanto, analizaremos las fotografías publicadas en los números seleccionados de cada diario, un total de sesenta y tres. 


\section{Hipótesis planteadas}

A partir de este análisis trataremos de aportar conclusiones sobre el tratamiento de las muertes analizadas en los medios, teniendo en cuenta el respeto a la propia imagen y la dignidad humana. Además, trataremos de añadir conclusiones acerca del tratamiento que la prensa le dio a las imágenes exhibidas.

La presencia de fotografías sangrientas que hieren la sensibilidad de los lectores, como las que analizamos en este trabajo, son habituales en los periódicos. Independientemente de la relevancia del suceso, el protagonista del mismo y su cobertura mediática, lo cierto es que las imágenes que suelen acompañar a este tipo de informaciones son espeluznantes. La sociedad necesita estar informada y que le cuenten lo que ocurre en el mundo, pero no necesita que le transmitan más miedo, más pánico, más aflicción, más aversión y más hechos que, en definitiva, en lugar de hacernos reflexionar nos atormentan.

Por ello, una de las hipótesis que planteamos es investigar hasta qué punto este tipo de fotografías de prensa pueden ser difundidas. Pretendemos saber dónde se encuentra el límite ético en el ámbito periodístico, pues a pesar de lo que se dice en el Código Penal, la Declaración Universal de los Derechos Humanos o el Código Ético y Deontológico de la Información sobre este asunto, tema que abordaremos más adelante, las imágenes con contenidos cruentos siguen acaparando las páginas de las cabeceras.

Asimismo, hablaremos de los criterios empleados por los medios de comunicación a la hora de seleccionar las imágenes sangrientas que difunden. Queremos saber si sus decisiones responden a la falta de información o, por el contrario, pretenden conmover y llamar la atención del lector. Esta hipótesis que planteamos guarda relación con el poder legítimo de los medios de comunicación, el cual deja de estar legitimado cuando se considera un derecho que hay que lograr por cualquiera de los caminos que conduzcan al poder. Esto lleva a que en numerosas ocasiones la realidad mediática se convierta en una realidad forzada por los propios medios de comunicación y sus profesionales.

Si echamos la vista atrás y recapacitamos en aquellas imágenes impactantes que hemos visto en las publicaciones en los últimos tiempos, podemos pensar que el medio de comunicación está cumpliendo lealmente con su deber de intermediario o que, por el contrario, se está extralimitando de sus funciones para captar una mayor audiencia, derivando la situación en un dilema ético-económico. Es obvio que han existido casos, y siguen existiendo, en los que se han sobrepasado los límites de la dignidad y la sensibilidad humana llegando a un extremo de morbosidad que no corresponde con un tratamiento ético de la información.

Otra de las hipótesis que planteamos guarda relación con la anterior, ya que comentaremos las connotaciones negativas que transmiten las fotografías analizadas a la sociedad, debido a la violencia que irradian. En los lectores de prensa los efectos de un ambiente más violento que se genera mediante las instantáneas publicadas pueden incrementar sutilmente la predisposición a responder de forma violenta, siendo ese aumento mayor en las personas que ya tienden a adoptar comportamientos agresivos. Así, las representaciones violentas acrecientan el riesgo de que se produzcan efectos anti- 
sociales, mientras que otras lo disminuyen. Por ello, es importante analizar el contexto de las escenificaciones violentas, con el fin de estimar el impacto en los lectores.

Del mismo modo, plantearé otras cuestiones que estarán relacionadas con las mencionadas anteriormente. Lo que pretendemos es buscar el punto de equilibrio entre los derechos a la intimidad y al honor y el derecho a la información. No entraremos en cuestiones estilísticas ni similares, ya que nos centraremos en el análisis de contenido.

\section{Análisis fotográfico}

Una vez realizado el análisis, se puede afirmar que tras examinar los 7 números, de los tres diarios, posteriores al día de los fallecimientos de los líderes, de los 63 periódicos estudiados hemos encontrado fotografías de Sadam en 6 números, de Bin Laden en 3 y de Muamar en 11. Se han hallado 62 instantáneas, de las que 19 fueron difundidas en $A B C, 23$ en El País y 20 en El Mundo. En los tres casos, predominan las imágenes de tamaño mediano y grande, siendo menor la presencia de fotografías pequeñas. Las tres cabeceras han difundido imágenes similares, en muchas ocasiones las mismas, ya que habían sido divulgadas por la televisión estatal iraquí en el caso de Husein, la agencia Reuters hacía públicas las fotografías en las que vemos los hombres de Bin Laden abatidos y las instantáneas de Gadafi pertenecían a capturas de vídeos que habían sido propagados por la red.

Se ha analizado lo que dicen los textos de regulación y autorregulación sobre los derechos que se quebrantan en las imágenes estudiadas. Así, los documentos gráficos examinados vulneran el artículo 12 de la Declaración Universal de los Derechos Humanos, el artículo 18 del Convenio Europeo de Derechos Humanos, el artículo 18 de la Constitución Española y el artículo 197 del Código Penal. En cuanto a los textos de autorregulación, las fotografías publicadas quebrantan el punto 4 del código deontológico de la Federación de Asociaciones de Periodistas de España, el punto 9 del Código Deontológico del Colegio de Periodistas de Cataluña, el artículo 13 del Código Deontológico del Sindicato de Periodistas de Madrid, el apartado 1.2.11 y el 1.2.12 del Libro de Estilo Vocento, el punto 5.4. del Libro de Estilo El País, el apartado dedicado al Respeto a la Intimidad en el Libro de Estilo $A B C$, y el capítulo 2.A y 8.B del Libro de Estilo El Mundo.

\section{Conclusiones}

En los documentos gráficos que se han encontrado en la investigación, podemos observar a Sadam en la horca con la soga en el cuello y, posteriormente, ejecutado; a los miembros del personal de Osama ensangrentados tras ser asesinados por el comando norteamericano; y a Gadafi, en condiciones pésimas, durante su lucha contra los rebeldes hasta alcanzar la muerte. Ahora es el momento de preguntarse si ¿son legítimas estas representaciones de los fallecidos o simplemente responden al factor del morbo y del impacto y forman parte del negocio de la información?

Hemos visto como tres de las cabeceras más importantes de nuestro país quebrantan los derechos básicos de los que goza el hombre: derecho al honor, a la intimidad y a la propia imagen. Las fotografías vulneran las leyes que recogen la Constitución Española, el Código Penal, la Declaración Universal de los Derechos Humanos, el 
Convenio Europeo de Derechos Humanos, así como mecanismos e instrumentos de autorregulación propios del mundo periodístico.

Hemos comprobado como las imágenes publicadas en ABC, El País y El Mundo sobre las muertes de los líderes no aportan información a la noticia, pues simplemente apoyan y corroboran lo que afirma el texto. Por eso nos preguntamos ¿por qué acrecentar la gravedad del asunto que se trata con documentos gráficos de tanta crudeza? Asimismo, el hecho de que los diarios coincidan en la publicación de las mismas fotografías demuestra la existencia de una rutina periodística en la selección de imágenes, pero si las instantáneas que se repiten son las de mayor dureza puedo deducir que la finalidad de esa elección responde a la teoría de más sangre, más morbo, mayor impacto.

En los casos que se han analizado, existe intromisión en la vida íntima de las personas ya que para llevar a cabo la transmisión de una información necesitaron emitir imágenes sobrecogedoras innecesarias que causaran impacto en los receptores. Debe estar en juego algo realmente valioso e importante para apelar a ese interés general o público. Determinar qué fotografías merecen ese carácter excepcional es siempre una cuestión abierta. La experiencia del periodista, su conocimiento y su sentido común ayudarán a detectarlo. Pero siempre habrá casos complejos y difíciles, en los que el periodista tendrá que estar guiado por una intención honesta. No son criterios adecuados la rapidez, la exclusividad, la competencia por la audiencia y la información como negocio o mercancía.

Una vez realizado el trabajo podemos afirmar que las imágenes publicadas pueden llegar a herir la sensibilidad de los seres humanos y a provocar efectos negativos en su persona. Estas fotografías tan duras en vez de crear impacto pueden ocasionar en el receptor el efecto inverso, es decir, que le resulten tan desagradables que el lector abandone la información, impidiendo de este modo realizar una reflexión sobre la lectura. Por lo tanto, la finalidad de la difusión de estas imágenes no es la concienciación social, ya que la repetición de estas fotos podrían generar insensibilización e indiferencia entre el público.

Por estas razones, nos hacemos eco de una cuestión llamativa que encontramos en los estudios llevados a cabo. En el apartado dedicado al análisis de las instantáneas publicadas de Sadam Husein, vemos como tras propagar imágenes de la muerte del ex dirigente de Irak los tres diarios divulgaban una noticia en la que nos informaban de que varios niños de distintas partes del mundo perdieran la vida imitando las imágenes de Sadam en la horca. Esto demuestra la impresión que causaron estas fotografías en estos pequeños y la falta de ética que existe en los medios de comunicación.

Este artículo que hemos realizado nos hace pensar en un tipo de periodismo alternativo al actual. Una adecuada sintonía entre el texto escrito y la fotografía permitiría otorgarle a las imágenes el contexto necesario para informar, sin tener que llegar a quebrantar los derechos de los que gozamos las personas, y por los que tanto hemos luchado y seguimos haciéndolo.

No debemos olvidar que los ciudadanos tienen derecho a ser informados pero que las víctimas tienen derecho a la intimidad. Por esta razón, los medios de comunicación y los profesionales de la información tienen la obligación de ser responsables y actuar 
con humanidad, honestidad y con mayor sensibilidad ante casos tan delicados como los que hemos tratado en este trabajo.

\section{Referencias bibliográficas}

ALONSO, Manuel y MATILLA, Luis (1990): Imágenes en acción. Madrid, Ediciones Akal.

ABREU, Carlos (2004): "El análisis cualitativo de la foto de prensa”, en Revista Latina de Comunicación Social, núm. 57, enero - junio. La Laguna (Tenerife). http://www.ull.es/publicaciones/latina/20040757abreu.htm (28-03-2012)

BARRET, Terry (1990): Criticizing Photographs. An Introduction to Understanding Images. USA, The Ohio State University, Mayfield Publishing Company.

BOLETÍN OFICIAL DEL ESTADO (BOE, 1978): “Constitución Española”, en http://www.boe.es/buscar/act.php?id=BOE-A-1978-31229

BOLETÍN OFICIAL DEL ESTADO (BOE, 1995): “Ley Orgánica 10/1995, 23 de noviembre, del Código Penal", en http://www.boe.es/buscar/act.php?id=BOE-A1995-25444

El PAÍS (2002): Libro de estilo El País. Madrid, El País, p. 69.

FEDERACIÓN DE ASOCIACIONES DE PERIODISTAS DE ESPAÑA (2010): “Código Deontológico", en Periodistas FAPE: http://www.fape.es/codigo-deontologico.htm

MARTÍNEZ DE SOUSA, José (2003): Libro de Estilo Vocento. Gijón, Trea.

MORENO, Javier (2006, 2007 y 2011): artículos publicados en El País: 31 de diciembre de 2006; 2 y 6 de enero de 2007; 5 de mayo de 2011; y 21, 22 y 23 de octubre de 2011

RAMÍREZ, Pedro J. (2006 y 2007): artículos publicados en El Mundo: 31 de diciembre de 2006; 2, 5 y 6 de enero de 2007; 5 de mayo de 2007; y 21, 22, 23 y 25 de octubre de 2007.

RAMOS FERNÁNDEZ, Fernando (1996): La ética de los periodistas. Pontevedra, Diputación de Pontevedra, p. 152.

RUBIDO, Bieito (2011): artículos publicados en ABC: 5 de mayo y 21, 22, 23 у 25 de octubre.

SINDICATO DE PERIODISTAS DE MADRID (2010): “Código Deontológico", en Sindicato de Periodistas de Madrid: http://www.sindicato-periodistas.es/docs/basicos/codigo_deontologico.pdf

UNESCO OFICINA REGIONAL DE EDUCACIÓN PARA AMÉRICA LATINA Y EL CARIBE (2008): Declaración Universal de los Derechos Humanos: http://unesdoc.unesco.org/images/0017/001790/179018m.pdf

UNIDAD EDITORIAL (1996): Libro de Estilo. Madrid, Temas de Hoy, pp. 30-31 y 106-111. 
UNIVERSIDAD DE SANTIAGO DE COMPOSTELA, CENTRO DE ESTUDIOS Y DOCUMENTACIÓN EUROPEA: "Convenio Europeo para la protección de los Derechos Humanos y las libertades fundamentales", en http://www.usc.es/es/servizos/cede/dereitosfundamentais/convenio.html

VIGARA TAUSTE, Ana María (2001): Libro de Estilo de ABC. Barcelona, Ariel, pp. 176-177.

ZARZALEJOS, J.A. (2006 y 2007): Artículos publicados en ABC: 31 de diciembre de 2006 y 2, 4, 5 y 6 de enero de 2007.

\section{Esperanza POUSO TORRES}

Universidade de Vigo

Licenciada en Periodismo (U. Complutense de Madrid)

esperanzapousotorres@gmail.com 